\title{
Analysis of organismic and population characteristics of the coenopopulations of Dracocephalum nutans $\mathrm{L}$.
}

\author{
Gulnora Denisova $^{1^{*}}$, Alexey Astashenkov ${ }^{1}$ \\ ${ }^{1}$ Central Siberian Botanical Garden SB RAS, 630090 Novosibirsk, Russia
}

\begin{abstract}
On the study of the mechanisms of sustainable development of populations of the widespread species D. nutans presents the results in the paper. Analysis of organism and population traits showed that in unformed communities, the species has maximum values of all selected traits. As a result, the comparison of points has been found to be associated with environmental and censorship conditions. Depending on the environmental factors, different types of ontogenetic spectrums are formed (left-sided, centered, right- sided).
\end{abstract}

\section{Introduction}

One of the main tasks for biodiversity conservation is studying the mechanisms of adaptation of plant at different levels of the organization. D. nutans is a species that is part of the natural flora of Eurasia. With the help of a score estimate of organismal and population characteristics, it is possible to assess the state of coenopopulation of the species and to identify the characteristics of the population organization of the species in different ecological and coenotical conditions.

Dracocephalum nutans L. - sympodia taprooted oligocarpous plants (Lamiaceae) [1].

The aim of the work is to assess the state of the coenopopulation (CP) of D. nutans in different ecological -phytocenotic conditions of southern Siberia

\section{Materials and Methods}

The study of the coenopopulation of D. nutans in a variety of cenosis of Tuva, the Altai Mountains and Hakassia was conducted.

Tuva: CР 1 studied in a meadow with Pentaphylloides fruticosa (L.) O. Schwars. и Salix trianda L. on the banks of the creek of the ridge Sangilene. The total cover reached is $30-35 \%$; CP 2 - in a serial group with Achillea millefolium L. on a pebble, cover $15-20 \%$.

\footnotetext{
* Corresponding author: gulnoria@mail.ru
} 
Altai Mountains: CP 3 - on the degraded meadow steppe, total cover 80\%; CP 4 - in the meadow steppe bushed Spiraea trilobata L., cover $85 \%$. CP 5 - in the highmountane petrophyte steppe, total cover $45-50 \%$. CP 6 - in a highmountane steppe on the bottom of a temporary watercourse, cover $35-40 \%$.

Hakassia: CP 7 - in the petrophyte steppe bushed Caragana pygmaea (L.) DC. and Spiraea hypericifolia $\mathrm{L}$., total cover $70-80 \%$.

\section{Results and Discussion}

The state of the CP was assessed according to the method of L.B. Zaugol'nova [2], based on the analysis and comparison of organismic and population characteristics. The features were selected according to their information content (table).

Table. Morphological and population characteristics of coenopopulations of Dracocephalum nutans L.

\begin{tabular}{|c|c|c|c|c|c|c|c|}
\hline \multirow[t]{2}{*}{ Character } & \multicolumn{7}{|c|}{ Coenopopulations } \\
\hline & 1 & 2 & 3 & 4 & 5 & 6 & 7 \\
\hline \multicolumn{8}{|c|}{ Organism characters } \\
\hline $\begin{array}{l}\text { Number of generative } \\
\text { shoots, pc. }\end{array}$ & $\frac{4.6}{3}$ & $\frac{13.4}{5}$ & $\frac{3.6}{2}$ & $\frac{2.3}{1}$ & $\frac{4.8}{3}$ & $\frac{5.1}{3}$ & $\frac{4}{2}$ \\
\hline $\begin{array}{l}\text { Height of the generative } \\
\text { shoot, } \mathrm{cm} \text {. }\end{array}$ & $\frac{15.1}{1}$ & $\frac{24.7}{3}$ & $\frac{48.2}{5}$ & $\frac{27.3}{3}$ & $\frac{21.2}{2}$ & $\frac{16.7}{2}$ & $\frac{42.1}{5}$ \\
\hline Flowers per shoot, pc. & $\frac{43.5}{2}$ & $\frac{94.9}{4}$ & $\frac{140.6}{5}$ & $\frac{34.5}{1}$ & $\frac{59}{2}$ & $\frac{64.7}{3}$ & $\frac{98.4}{4}$ \\
\hline $\begin{array}{l}\text { Phytomass of mature } \\
\text { generative individual, gr. }\end{array}$ & $\frac{2.4 \pm}{2}$ & $\frac{7.3}{5}$ & $\frac{5.1}{4}$ & $\frac{1.5}{1}$ & $\frac{2.8}{2}$ & $\frac{2.5}{2}$ & $\frac{3.9}{3}$ \\
\hline $\begin{array}{l}\text { Potential seed } \\
\text { productivity, pc. }\end{array}$ & $\frac{824}{2}$ & $\frac{6032}{5}$ & $\frac{788}{2}$ & $\frac{344}{1}$ & $\frac{3152}{3}$ & $\frac{1776}{3}$ & $\frac{1632}{2}$ \\
\hline \multicolumn{8}{|c|}{ Population characters } \\
\hline $\begin{array}{l}\text { Share of the undergrowth } \\
(j-v), \%\end{array}$ & $\frac{77.5}{5}$ & $\frac{40.2}{2}$ & $\frac{83.9}{5}$ & $\frac{39.5}{2}$ & $\frac{52.4}{3}$ & $\frac{34.9}{2}$ & $\frac{25.6}{1}$ \\
\hline Share of the $\mathrm{g} 1-\mathrm{g} 2, \%$ & $\frac{19.2}{2}$ & $\frac{46.4}{5}$ & $\frac{8.3}{1}$ & $\frac{29}{3}$ & $\frac{32.5}{4}$ & $\frac{42}{4}$ & $\frac{53.6}{5}$ \\
\hline Share of the $\mathrm{g} 3-\mathrm{s}, \%$ & $\frac{3.3}{1}$ & $\frac{13.4}{3}$ & $\frac{7.8}{2}$ & $\frac{31.5}{5}$ & $\frac{15.1}{3}$ & $\frac{23.1}{4}$ & $\frac{20.8}{4}$ \\
\hline Density, $\mathrm{pc} . / \mathrm{m}^{2}$. & $\frac{43.2}{5}$ & $\frac{5.9}{2}$ & $\frac{31.1}{4}$ & $\frac{16.2}{3}$ & $\frac{25.9}{3}$ & $\frac{46}{5}$ & $\frac{4.4}{1}$ \\
\hline
\end{tabular}

Note: in the numerators - the average value of the traits, $\mathrm{cm}$; the denominator is scores (on a fivepoint scale). Pc. - cm. - gr.- m

The biomass of an individual is a trait that is considered one of the most informative, assessing the vitality of plants, but its indicators can be made up of the values of different characteristics of an individual. Thus, in CP 2, plants growing in an unformed community have the highest aboveground biomass ( 5 points). In individuals of this $\mathrm{CP}$, it is determined by the maximum number of generative shoots. Plants CP 3, 7 have average biomass values; however, despite the fact that in CP 3 the number of shoots is lower than in CP 7, the biomass of individuals in CP 3 is higher due to their greater height (table). In CPs 1, 4, 5, 6, 
the lowest indices of all organismic traits are noted, which is reflected in the insignificant biomass of plants. Low values of traits are associated with the growth of D. nutans individuals in high mountains and sodding of coenosis due to Festuca valesiaca Gand, Stipa capillata L., Carex pediformis C.A. Mey.

A change in the indices of an individual's generative elements entails a redistribution of the values of other related traits. Thus, in most of the studied CPs, medium and low values of potential seed productivity (PSP) were noted (from 788 to $3152 \mathrm{pcs} /$ individual, which corresponds to $2-3$ points). The exception is CP 2, where the maximum PSP is formed in individuals $-6032 \mathrm{pcs} /$ individual (5 points), and CP 4, where this indicator is minimal 344 pcs/individual (1 point). The wide range of PSP variation between the studied CP is associated with a high scatter in the values of such traits as "the number of flowers per shoot" and "the number of generative shoots". In general, the change of the values of various elements of individuals changes towards a decrease with an increase total cover of coenosis.

Assessment of organismic characteristics of CP of D. nutans by showed that in the CP studied in the unformed community (CP 2) has the sum of points is maximum (22 points). These values are achieved due to the lack of competition between species and low total cover of coenosis $(15-20 \%)$. In CP 1, 4, the sum of organismic traits is minimal - 10 and 7 points, respectively. Low values of individuals are associated with their growth in high mountains as part of a bush community and a heavily sodded meadow steppe. The rest of the $\mathrm{CP}$ had average values in terms of the total points (11-16 points).

Analysis of CP based on population characteristics showed that in most CP prevails the proportion of the pregenerative fraction. High values of this trait are associated with abundant seed renewal, which is a characteristic biological feature of $D$. nutans. As a result of the accumulation of pregenerative fraction is formed a left-sided type of spectrum, which corresponds to the characteristic ontogenetic spectrum and reflects the reactive type of strategy of the species [1]. The proportion of pregenerative fraction is low in CP 7. At the same time, a high proportion of the mature generative fraction is noted in $\mathrm{CP} 7$, which leads to the formation of a centered type of spectrum. The old group of plants accumulates in $\mathrm{CP}$ 4 , and the right-sided type of the spectrum is formed. The deviation from the characteristic spectrum in CP 4, 7 is associated with the high sodding and bushiness of the communities, which negatively affects the development of individuals of the pregenerative period.

The density of individuals ranges from 4.4 to 46 ind. $/ \mathrm{m}^{2}$ ( $3-5$ points) in the CP. This fluctuation in numbers is associated with the different density of the phytocenosis and the characteristics of the substrate and relief. The maximum and high abundance is noted in the streamside communities (CP 1,6), the minimum in the serial grouping with Achillea millefolium L. (CP 2) and in the petrophytic steppe of the shrub Caragana pygmaea (L.) DC. and Spiraea hypericifolia L. (CP 7).

\section{Conclusion}

Thus, the highest sum of points of organismic and population traits was found in the CP studied in the unformed community (CP 2) and in the fallow (CP 3) (34, 30 points, respectively). This indicates that these cenopopulations are in the best condition. The minimum values $(23,20$ points, respectively) were established in the CP located in the meadow (CP 1) and in the meadow steppe (CP 4) with shrub Pentaphylloides fruticosa, Salix trianda, and Spiraea trilobata. Despite the minimal indices of organismic traits and a low PSP (344, 824 erem), the CP 1.4 has a left-sided type of spectrum and a rather high density of individuals. Which indicates that the CPU 1,4 is in a satisfactory condition. Intermediate values $(24-27$ points) were found in $\mathrm{CP}$ in steppe (CP 5, 6, 7) communities, which indicate the normal state of CP of D. nutans. 
The work was carried out the project of the State Assignment of Central Siberian Botanical Garden of the Siberian Branch of the Russian Academy of Sciences № AAAAA21-121011290026-9.

\section{References}

1. G. R. Denisova, Rastitel'nyye resursy. 43 (3): 25-34. (2007)

2. L. B. Zaugolnova, Population structure of seed plants and problems of their monitoring. (St. Petersburg, 1994). 